\title{
Cyclin A1 is associated with poor prognosis in oesophageal squamous cell carcinoma
}

\author{
XIAOTING HE ${ }^{1,2^{*}}$, SUQING LI $^{1 *}$, WEIHONG SHI ${ }^{3}$, QINGFENG LIN ${ }^{4}$, JIAN MA $^{1}$, \\ YANG LIU ${ }^{5}$, TINGTING FENG ${ }^{6}$ and XIUFENG CAO ${ }^{1,7}$ \\ ${ }^{1}$ Department of Surgical Oncology, Nanjing First Hospital, Nanjing Medical University, Nanjing, Jiangsu 210000; \\ ${ }^{2}$ Department of Medical Oncology, The Affiliated Wuxi People's Hospital of Nanjing Medical University, Wuxi, \\ Jiangsu 214043; ${ }^{3}$ Department of Clinical Medicine, Yancheng Vocational Institute of Health Sciences, Yancheng, \\ Jiangsu 224005; ${ }^{4}$ Department of Medical Oncology, Jiangyin People's Hospital, Jiangyin, Jiangsu 214400; \\ ${ }^{5}$ Department of Pharmacy, No. 401 Hospital of Chinese People's Liberation Army, Qingdao, Shandong 266071; \\ ${ }^{6}$ Institute of Biology and Medical Sciences, Soochow University, Suzhou, Jiangsu 215123; 7 Department of Surgery, \\ Nanjing Medical University, Taikang Xianlin Drum Tower Hospital, Jiangsu 210000, P.R. China
}

Received April 23, 2018; Accepted April 2, 2019

DOI: $10.3892 / \mathrm{ol} .2019 .10377$

\begin{abstract}
Dysregulation of cyclin A1 (CCNA1) is implicated in the carcinogenesis, progression and metastasis of many types of solid tumours. In the present study, an mRNA single-channel expression profile chip experiment revealed that the CCNA1 mRNA levels in oesophageal squamous cell carcinoma (ESCC) were increased $>10$-fold compared with those in the adjacent non-cancer tissues. Reverse transcription-quantitative polymerase chain reaction and immunohistochemistry analyses were performed to additionally investigate the role of CCNA1 in the development and progression of ESCC in patients treated by radical resection of the oesophagus. The association between CCNA1 mRNA expression and the clinicopathological parameters of patients with ESCC was statistically analysed. The results indicated that upregulation of CCNA1 occurred in $~ 70 \%$ of patients with ESCC, and increased CCNA1 mRNA expression was significantly associated with advanced clinical stage, lymph node metastasis, invasiveness and poor clinical outcome, including disease-free survival and overall survival rates. Taken together, the data suggested that CCNA1 had an important function in ESCC
\end{abstract}

Correspondence to: Professor Xiufeng Cao, Department of Surgical Oncology, Nanjing First Hospital, Nanjing Medical University, 68 Changle Road, Nanjing, Jiangsu 210000, P.R. China

E-mail: cxf551101@sina.com

Ms. Tingting Feng, Institute of Biology and Medical Sciences, Soochow University, 199 Renai Road, Suzhou, Jiangsu 215123, P.R. China

E-mail: fengting157@163.com

*Contributed equally

Key words: cyclin A1, oesophageal squamous cell carcinoma, clinicopathological parameters, prognosis, survival development and progression, and may serve as a prognostic biomarker and therapeutic target in ESCC.

\section{Introduction}

Oesophageal cancer is one of the leading causes of cancer mortality worldwide (1). Oesophageal squamous cell carcinoma (ESCC) is the major histological type of oesophageal cancer in Eastern Asia (>90\%). Epidemiological evidence suggests that carcinogen exposure and nutritional deficiency may be major risk factors for oesophageal cancer development (2). Genetic susceptibility may be an even more significant risk factor in high incidence areas of Northern China, such as variants in the phospholipase $\mathrm{C}$ epsilon 1 gene at 10q23. The 5-year survival rate of patients with ESSC is $<20 \%$, due to the lack of effective tools for early diagnosis and treatment (3). Therefore, it is crucial to understand the pathogenesis of ESCC. At present, the molecular basis for the development and progression of ESCC remains unclear.

Cyclin A1 (CCNA1) is an A-type cyclin characterised by a typical periodicity in protein abundance throughout the cell division cycle. CCNA1 binds cyclin-dependent kinase 2 (CDK2) and cell division cycle 2 (CDC2) kinases in the $\mathrm{S}$ and $\mathrm{G} 2$ phases, respectively, which results in 2 distinct kinase activities, and thereby regulates separate functions in the cell cycle $(4,5)$. This cyclin has also been demonstrated to bind to important cell cycle regulators, including retinoblastoma $(\mathrm{Rb})$ family proteins, transcription factor E2F-1, and the p21 family proteins (5-8). CCNA1 was initially identified as a protein essential for spermatogenesis and leukaemogenesis $(9,10)$; however, evidence indicates that dysregulation of CCNA1, including its methylation or hypermethylation (11-14), is closely associated with carcinogenesis, cancer progression and metastasis in several solid tumour types $(5,7,15,16)$. Furthermore, hypermethylation of the CCNA1 promoter is a potential marker for distinguishing the histopathological stage during multistep carcinogenesis $(13,17)$, which indicates 
its important role in early diagnosis. Hypermethylation of CCNA1 may be used as a tool for the identification of head and neck squamous cell carcinoma (HNSCC) subjects at risk of developing second primary carcinomas $(18,19)$, suggesting its potential effect on patient prognosis. In addition, CCNA1 methylation is a potential predictive marker for chemotherapy sensitivity (20-22), which may aid in the development of effective therapy regimens.

Although the evidence of CCNA1 carcinogenicity in humans is compelling, its involvement in ESCC has not yet been reported. The present study demonstrated that CCNA1 mRNA was significantly upregulated in ESCC, and that its expression was associated with poor cell differentiation, advanced clinical stage, lymph node metastasis and invasiveness. Patients with high levels of CCNA1 had decreased disease-free survival (DFS) and overall survival (OS) rates, compared with patients with decreased levels of CCNA1. These data suggested that CCNA1 may serve a crucial role in the tumourigenesis and progression of ESCC and identified CCNA1 as a potential prognostic biomarker and therapeutic target in ESCC.

\section{Materials and methods}

Ethics statement. The present study was approved by the Ethics Committee of Nanjing Medical University Cancer Centre (Nanjing, China). All patients provided written informed consent. All specimens were handled and stored anonymously according to ethical and legal standards.

Study population. Tumour samples were obtained from December 2007 to January 2012, from patients with pathologically confirmed ESCC $(n=78)$ during radical surgery of the oesophagus at the Affiliated Nanjing Hospital of Nanjing Medical University (Nanjing, China). No patients had received antitumour therapy, including chemotherapy, radiotherapy or chemoradiation prior or subsequent to the surgery. The adjacent non-cancerous tissue was defined as tissue $\geq 2 \mathrm{~cm}$ from the edge of the tumour. The clinicopathological parameters of the 78 patients with ESCC were obtained from medical records and pathology reports. The ESCC specimens were staged in accordance with the 7 th edition of the American Joint Committee on Cancer/Union for International Cancer Control tumor, node, metastasis (TNM) staging system (23). The grading and histopathological subtyping of the ESCC specimens was based on WHO Classification of Tumors of the Digestive System (24). Patient consent was obtained prior to use of the clinical materials for research purposes. The patients regularly attended follow-up visits. OS was defined as the interval between the dates of surgery and mortality or last observation. DFS was defined as the interval from the date of surgery to that of recurrence, the last follow-up or mortality. Data were censored at the last follow-up visit for surviving patients with no disease recurrence.

RNA isolation and Agilent mRNA single-channel expression profile chip experiment. Total RNA was extracted from 5 representative paraffin blocks of cancerous and paired adjacent non-cancerous tissues using an EasyPure RNA kit (Beijing Transgen Biotech Co., Ltd.), then purified and fluorescently labelled using a Crystal core ${ }^{\circledR}$ cRNA amplification marker kit (Beijing CapitalBio Technology Co., Ltd.), according to the manufacturer's protocol. The chip was scanned using Agilent G2565CA Microarray Scanner (Agilent Technologies, Inc.) to obtain hybrid images. The Feature Extraction image analysis software was used to analyse the chip image and convert the image signals into digital signals. The raw data were inputted into GeneSpring GX 10 software (Agilent Technologies Inc.), and the signal was normalized by the percentile shift method. Then, the differential genes were confirmed by a standard of absolute fold change $\geq 2$.

Reverse transcription quantitative polymerase chain reaction $(R T-q P C R)$. Total RNA was extracted by Trizol reagent (Invitrogen; Thermo Fisher Scientific, Inc.), and reverse transcribed to cDNA by the PrimeScript ${ }^{\mathrm{TM}}$ RT reagent kit (Invitrogen; Thermo Fisher Scientific, Inc.), according to the supplier's protocol. The following primers were used: Cyclin A1 forward, 5'-CTCCTCTCCCAGTCTGAAGA-3'; cyclin A1 reverse, 5'-CAGGAAGTTGACAGCCAGAT-3'; GAPDH forward, 5'-AACAGCGACACCCACTCCTC-3'; GAPDH reverse, 5'-GGAGGGGAGATTCAGTGTGGT-3'. The two-step PCR protocol was used as follows: Initial denaturation at $95^{\circ} \mathrm{C}$ for $30 \mathrm{sec}$, followed by 40 cycles of denaturation at $95^{\circ} \mathrm{C}$ for $1 \mathrm{~min}$ and annealing at $60^{\circ} \mathrm{C}$ for $34 \mathrm{sec}$, followed by an extension at $95^{\circ} \mathrm{C}$ for $15 \mathrm{sec}, 60^{\circ} \mathrm{C}$ for $1 \mathrm{~min}$ and $95^{\circ} \mathrm{C}$ for 5 sec. $\mathrm{qPCR}$ was performed using $\mathrm{SYBR}^{\circledR}$ Premix Ex $\mathrm{Taq}^{\mathrm{TM}}$ II (Takara) and an ABI 7500 Real-time PCR system and the StepOnePlus ${ }^{\mathrm{TM}} 2.0$ software (Bio-Rad Laboratories, Inc.). The real-time values were averaged for each sample and compared using the $\mathrm{Ct}$ method. The relative expression level of the target gene, defined as a fold change, was calculated using the $2^{-\Delta \Delta \mathrm{Cq}}$ (25) method, where $\Delta \Delta \mathrm{Cq}=$ mean $\mathrm{Cq}_{\mathrm{CCNA}}$-mean $\mathrm{Cq}_{\mathrm{GAPDH}}$. A total of 2 independent experiments were performed to analyse the relative gene expression, and each sample was examined in triplicate.

Immunohistochemistry (IHC). For IHC analysis of CCNA1 protein expression, 20 paraffin-embedded ESCC tumour specimens $(n=10)$ and the corresponding normal epithelial samples $(n=10)$ were selected. The reagents used in immunohistochemistry were purchased from Fuzhou Maxim Biotechnology Development Co., Ltd. Briefly, tissue sections were cut from the paraffin blocks $(5 \mu \mathrm{m})$ and mounted on microscope slides. Slides were placed in $60^{\circ} \mathrm{C}$, baked for $20 \mathrm{~min}$ before being deparaffinised with xylene, then orderly soaked in anhydrous ethanol, $95 \%$ ethanol and $75 \%$ ethanol, and blocked with $10 \%$ normal goat serum at room temperature for $30 \mathrm{~min}$. The slides were subsequently incubated with a rabbit polyclonal antibody against CCNA1 (cat.no., ab118897, Abcam) at a dilution of 1:100 at $4^{\circ} \mathrm{C}$ overnight, followed by incubation with biotinylated goat anti-rabbit immunoglobulin (cat. no., KIT-5004) at a dilution of 1:100 for $60 \mathrm{~min}$ at $37^{\circ} \mathrm{C}$. CCNA1 expression was evaluated as the percentage of tumour cells with positive staining at each high-power field with a light microscope (OLYMPUS BX46; Olympus Corporation; magnification, x100), and at least 5 HPFs were assessed. The H-score method (26) was used to analyse each sample on a continuous scale of 0-300. The percentage of cells at different staining intensities [no staining, weak (yellow), moderate (brown), or strong (dark brown)] was 

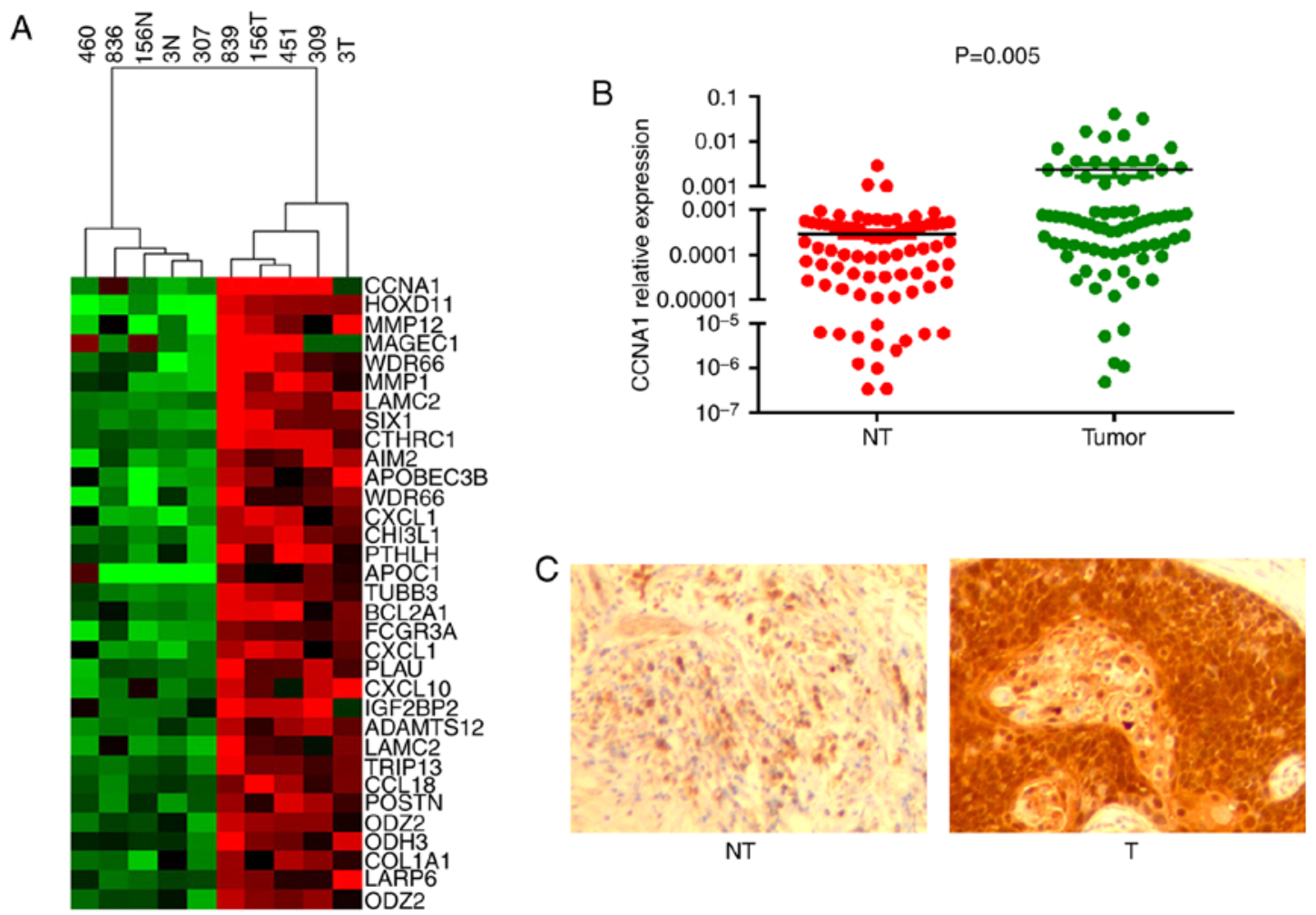

Figure 1. CCNA1 upregulation in ESCC. (A) A total of 5 mRNA single-channel expression profile chips all revealed that CCNA1 levels in ESCC (5 right-hand columns) were increased $>10$-fold compared with those in NTs (5 left-hand columns). (B) Cyclin A1 mRNA expression was significantly increased in the ESCC tissues compared with the matched adjacent NTs $(\mathrm{P}=0.005)$ using reverse transcription quantitative polymerase chain reaction. (C) Representative CCNA1 protein expression in a pair of ESCC (right) and adjacent NT (left) samples from 1 patient, detected by immunostaining with anti-CCNA1 antibody. Positive staining is indicated by brown colouring. Magnification, x100. CCNA1, cyclin A1; ESCC, oesophageal squamous cell carcinoma; NT, non-cancer tissues.

determined by visual assessment, with the score calculated using the formula: (Percentage of weakly stained tumour cells) $+(2 x$ percentage of moderately stained tumour cells $)+(3 x$ percentage of strongly stained tumour cells). Samples were subsequently classified as low (H-score <200; IHC negative) or high ( $\geq 200$; IHC positive) for CCNA1 protein expression.

Statistical analysis. All statistical analyses were performed using SPSS version 19.0 (IBM Corp.). Paired Student's t-test was used in the comparison of the relative expression levels of CCNA1 mRNA between tumour tissues and the adjacent non-cancer tissues (NTs). Pearson's $\chi^{2}$ test or Fisher's exact test and logistic regression analysis were used to examine the association between CCNA1 expression and the clinicopathological parameters. DFS and OS were estimated using the Kaplan-Meier method, with a 95\% confidence interval. Differences between survival curves were calculated using the log-rank test. Prognostic factors were examined by multivariate analyses using the Cox proportional hazards model. $\mathrm{P}<0.05$ was considered to indicate a statistically significant difference.

\section{Results}

CCNA1 is upregulated in ESCC tissues. All 5 mRNA chips revealed that CCNA1 mRNA levels in ESCC were increased $>10$-fold compared with those in the adjacent NTs $(\mathrm{P}=0.007$; Fig. 1A). RT-qPCR was performed for 78 pairs of primary ESCC tumours and their corresponding adjacent NTs. It was revealed that upregulation of CCNA1 mRNA was present in
55/78 (70.51\%) ESCC tumours, whereas upregulation was present in 23/78 of the adjacent NTs (29.49\%). The relative expression levels of CCNA1 mRNA were significantly increased in tumour tissues compared with the adjacent NTs $(\mathrm{P}=0.005$; Fig. 1B). IHC analysis indicated that cyclin A1-positive staining was present in 7/10 ESCC specimens (70\%) and 2/10 adjacent NTs (20\%), although there was no statistical difference $(\mathrm{P}=0.07)$. CCNA1 protein was primarily located in the nucleus of tumour cells, as indicated by the brown staining pattern (Fig. 1C).

CCNA1 upregulation is associated with ESCC progression. The association between CCNA1 mRNA expression levels and the clinicopathological features of ESCC were subsequently evaluated (Table I). The results revealed that CCNA1 upregulation was correlated with the tumour invasiveness $(\mathrm{P}=0.04)$, advanced clinical stage $(\mathrm{P}=0.001)$ and lymphatic metastasis $(\mathrm{P}=0.029)$. However, univariate analysis revealed that CCNA1 upregulation was not significantly associated with sex, age or cell differentiation. Binary logistic regression analysis indicated that the expression of CCNA1 was increased in cases with poor cell differentiation $(\mathrm{P}=0.01)$ and advanced clinical stage $(\mathrm{P}<0.001$; Table II). No distant metastasis cases were presented in the present study.

CCNA1 upregulation in tumour cells predicts poor prognosis. The 5-year survival rate of the ESCC patients enrolled in the present study was $24.36 \%$ (19/78). During the follow-up period, 53 patients $(67.95 \%)$ were diagnosed with tumour recurrence 
Table I. Association between CCNA1 expression and oesophageal squamous cell carcinoma clinicopathological characteristics.

\begin{tabular}{|c|c|c|c|c|}
\hline \multirow[b]{2}{*}{ Characteristics } & \multirow[b]{2}{*}{ Number } & \multicolumn{2}{|c|}{ CCNA1 expression } & \multirow[b]{2}{*}{ P-value } \\
\hline & & High (\%) & Low $(\%)$ & \\
\hline Age, years & & & & 0.777 \\
\hline$<60$ & 29 & $21(38.18)$ & $8(34.78)$ & \\
\hline$\geq 60$ & 49 & $34(61.82)$ & $15(65.22)$ & \\
\hline Sex & & & & 0.482 \\
\hline Male & 52 & $38(69.09)$ & $14(60.87)$ & \\
\hline Female & 26 & $17(30.91)$ & $9(39.13)$ & \\
\hline Cell differentiation & & & & 0.073 \\
\hline Well & 12 & $7(12.73)$ & $5(21.74)$ & \\
\hline Moderate & 56 & $38(69.09)$ & $18(78.26)$ & \\
\hline Poor & 10 & $10(18.18)$ & $0(0)$ & \\
\hline Tumour invasion depth & & & & 0.04 \\
\hline $\mathrm{T} 1$ & 7 & $3(5.45)$ & $4(17.39)$ & \\
\hline $\mathrm{T} 2$ & 18 & $10(18.18)$ & $8(34.78)$ & \\
\hline $\mathrm{T} 3$ & 53 & $42(76.36)$ & $11(47.83)$ & \\
\hline $\mathrm{T} 4$ & 0 & $0(0)$ & $0(0)$ & \\
\hline Lymph node metastasis & & & & 0.029 \\
\hline No & 51 & $31(56.36)$ & $20(36.36)$ & \\
\hline N1 & 22 & $19(34.55)$ & $3(13.04)$ & \\
\hline $\mathrm{N} 2$ & 5 & $5(9.09)$ & $0(0)$ & \\
\hline Distant metastasis & & & & - \\
\hline M0 & 78 & $55(100)$ & $23(100)$ & \\
\hline M1-X & 0 & $0(0)$ & $0(0)$ & \\
\hline Clinical stage & & & & 0.001 \\
\hline I & 19 & $8(14.55)$ & $11(47.83)$ & \\
\hline II & 33 & $23(41.82)$ & $10(43.48)$ & \\
\hline III & 26 & $24(43.64)$ & $2(8.70)$ & \\
\hline IV & 0 & $0(0)$ & $0(0)$ & \\
\hline
\end{tabular}

CCNA1, cyclin A1. P-values were calculated using Pearson's $\chi^{2}$ test or Fisher's exact test, as appropriate.

Table II. Binary logistic regression analysis between cyclin A1 expression and oesophageal squamous cell carcinoma clinicopathological characteristics.

\begin{tabular}{lrr}
\hline Variable & Hazard ratio (95\% confidence interval) & P-value \\
\hline Cell differentiation, well/moderate/poor & $\begin{array}{l}6.195(1.555-24.670) \\
5.114(2.063-12.676)\end{array}$ & 0.010 \\
Clinical stage, I/II/III & $<0.001$ \\
\hline
\end{tabular}

Variables were analysed by Pearson $\chi^{2}$ test or Fisher's exact test.

and progression. In the overexpression group, the median OS and DFS were 20 and 14 months, respectively. Univariate analysis demonstrated that high CCNA1 expression, advanced clinical stage, and higher $\mathrm{T}$ and $\mathrm{N}$ classifications predicted a shorter OS in ESCC, although multivariate analysis demonstrated that only overexpression of CCNA1 and advanced clinical stage were independent prognostic factors for ESCC (Table III). Kaplan-Meier analyses and log-rank tests revealed that patients with high CCNA1 expression had significantly shorter DFS $(\mathrm{P}=0.006)$ and $\mathrm{OS}(\mathrm{P}=0.003)$ rates, compared with the low CCNA1 expression group (Fig. 2).

\section{Discussion}

CCNA1 primarily functions in the meiotic cell cycle, but also contributes to the cell cycle progression in somatic cells (5). 
Table III. Analyses of prognostic parameters in patients with oesophageal squamous cell carcinoma.

\begin{tabular}{|c|c|c|c|c|}
\hline \multirow[b]{2}{*}{ Variables } & \multicolumn{2}{|c|}{ Univariate analysis } & \multicolumn{2}{|c|}{ Multivariate analysis } \\
\hline & $\mathrm{HR}(95 \% \mathrm{CI})$ & P-value & $\mathrm{HR}(95 \% \mathrm{CI})$ & P-value \\
\hline Clinical stage, I & & $<0.001$ & $7.535(2.656-21.371)$ & $<0.001$ \\
\hline II & $0.007(0.001-0.054)$ & & & \\
\hline III & $0.158(0.083-0.300)$ & & & \\
\hline Cell differentiation, well/moderate/poor & - & 0.905 & - & - \\
\hline Lymph node metastasis, N0/N1-N2 & $0.101(0.053-0.192)$ & $<0.001$ & - & - \\
\hline Tumour invasion depth, T1-T2/T3 & $0.164(0.069-0.387)$ & $<0.001$ & - & - \\
\hline Sex, male/female & $2.168(1.136-4.137)$ & 0.013 & - & - \\
\hline Age, $y,<60 / \geq 60$ & - & 0.697 & - & - \\
\hline CCNA1, low/high expression & $0.387(0.198-0.756)$ & 0.003 & $0.456(0.220-0.943)$ & 0.034 \\
\hline
\end{tabular}

HR, hazard ratio; CI, confidence interval; CCNA1, cyclin A1. P-values were obtained by univariable analysis, Kaplan-Meier analysis and the log-rank test.
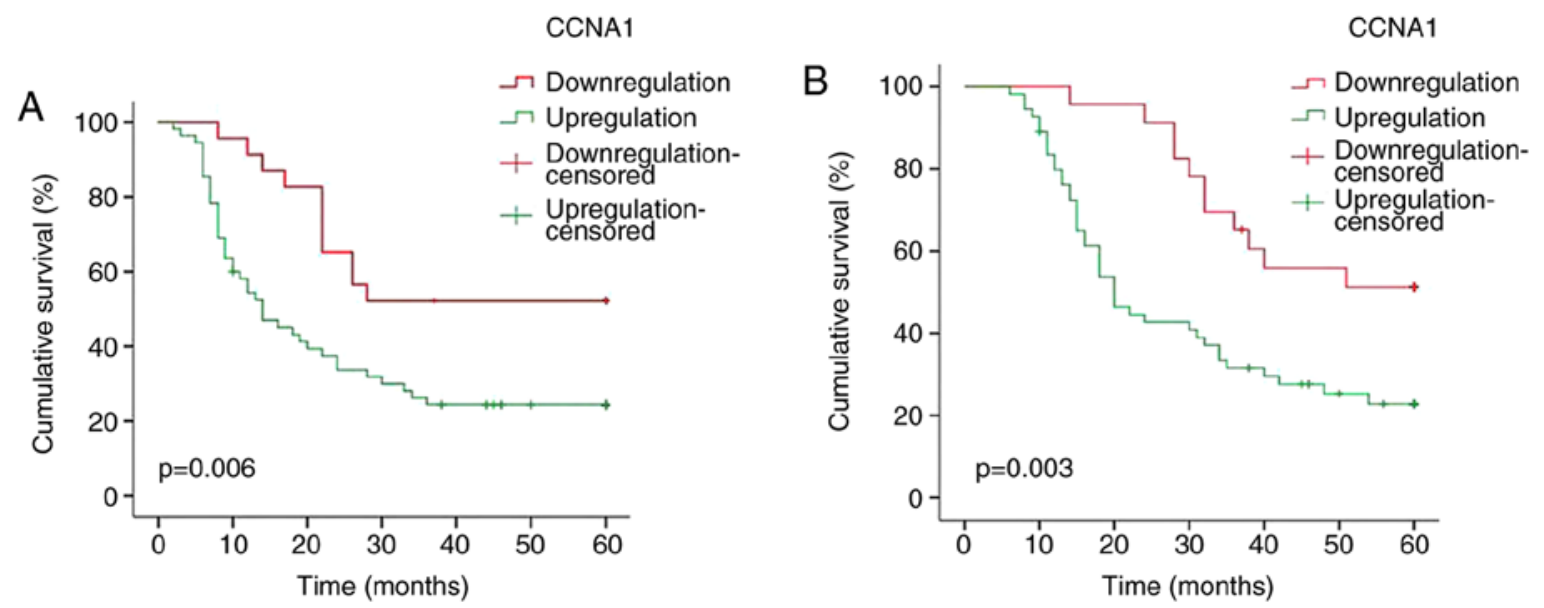

Figure 2. CCNA1 upregulation is associated with poor prognosis in patients with ESCC. Patients with increased levels (green line) of CCNA1 exhibited poorer (A) disease-free survival (log-rank $\mathrm{P}=0.006)$ and $(\mathrm{B})$ overall survival (log-rank $\mathrm{P}=0.003)$ compared with those with decreased CCNA1 expression (red line). CCNA1, cyclin A1.

In addition, CCNA1 has been demonstrated to serve as an oncogene and tumour suppressor $(7,27)$, with crucial roles in the carcinogenesis, progression and metastasis of several solid tumour types (11-16). In addition, CCNA1 is considered to be a promising tumour antigen for anticancer T-cell therapies $(28,29)$, and increased CCNA1 expression results in chemoresistance to certain cytotoxic drugs, including paclitaxel, doxorubicin and 5-fluorouracil $(20,22)$.

However, the role of CCNA1 in ESCC remains largely unknown; to the best of our knowledge, the present study is the first to describe the involvement of CCNA1 in ESCC. It was revealed that CCNA1 mRNA expression was significantly increased in the ESCC tissues compared with paired non-cancerous tissue using mRNA chips and RT-qPCR. Increased expression of CCNA1 protein was observed in ESCC tissues (70\% positive) compared with paired non-cancerous tissues (20\% positive) by IHC, which was consistent with the CCNA1 mRNA expression results. However, no statistical significance was observed; this discrepancy may be due to the small sample size. CCNA1 protein was predominantly located in the nucleus of tumour cells, where it may bind CDK 2 or CDC2 kinases to control the cell cycle at the G1/S or G2/M transitions $(5,7)$. This suggests that CCNA1 may have an important role in the development and progression of ESCC.

A tissue microarray study of 149 patients with bladder cancer revealed that CCNA1 expression predicts progression, and recent clinical evidence has demonstrated that CCNA1 contributes to cancer invasion via multiple cellular mechanisms $(30,31)$. Consistent with these data, the present study revealed that ESCC tumours with high CCNA1 expression were more invasive, prone to lymph node metastasis and in advanced clinical stages, suggesting a prognostic role of CCNA1 for ESCC progression. Furthermore, the data confirmed that increased levels of CCNA1 were associated with poorer cell differentiation. Therefore, CCNA1 expression has the potential to be used as a biomarker to determine whether adjuvant therapy following surgery is required. Survival analysis revealed that the poorer outcomes were associated with numerous factors, including 
high CCNA1 expression, advanced clinical stage, $\mathrm{T}$ and $\mathrm{N}$ classification and sex. However, only CCNA1 overexpression and advanced clinical stage were independent prognostic factors for ESCC survival. In agreement with previous data $(29,31,32)$, the data from the present study clearly demonstrated that a subset of patients with upregulated CCNA1 mRNA expression exhibited demonstrated DFS and OS rates. The present study suggested that CCNA1 may be an important oncogene in ESCC development and progression.

CCNA1 is an important cell-cycle regulator, and previous molecular studies have revealed that the oncogenic function of CCNA1 was closely associated with its effect on cellular proliferation (33-37). In addition, CCNA1 was functionally associated with vascular endothelial growth factor, matrix metalloproteinase (MMP)2, MMP9 and oestrogen receptor $\alpha$ to promote cancer progression (30,38-40). However, the particular molecular mechanism of CCNA1 in ESCC requires additional study.

Although the results of the present study require additional validation due to certain limitations, they elucidated the clinical importance of CCNA1 in ESCC progression. In particular, the effect of CCNA1 expression on survival was highlighted. The data presented suggested that CCNA1 was an important prognostic factor and a diagnostic molecular marker in ESCC. Furthermore, CCNA1 has potential as a novel therapeutic target in patients with ESCC.

\section{Acknowledgements}

The authors would like to thank Dr. Jian Zou and Ying Yin (Central Laboratory, Wuxi People's Hospital) for their advice and input. The authors acknowledge colleagues in the Department of Pathology (Wuxi People's Hospital) for providing the facilities.

\section{Funding}

The present study is supported by National Natural Science Foundation of China (grant no. 81672423), Jiangsu Natural Science Foundation (grant no. BK20151292), Jiangsu Provinceal Medical Innovation Team of the Project of Invigorating Health Care through Science, Technology and Educationg, and the 333 Project Foundation of Jiangsu Province (grant no. BRA2014355).

\section{Availability of data and materials}

The datasets used and/or analyzed during the present study are available from the corresponding author on reasonable request.

\section{Authors' contributions}

$\mathrm{XH}, \mathrm{XC}$ and SL were responsible for the conception and design of the study. $\mathrm{XH}, \mathrm{TF}$ and SL developed the methodology. XH, QL and XC were responsible for the acquisition of data, including recruitment and management of patients and provision of facilities. $\mathrm{XH}, \mathrm{TF}, \mathrm{JM}, \mathrm{QL}, \mathrm{WS}$ and $\mathrm{YL}$ anlaysed and interpreted the data, including statistical analysis, biostatistics and computaional analysis. $\mathrm{XH}$ and TF were responsible for writing and revision of the manuscript. XH and XC provided administrative, technical and material support, including reporting or organizing data, and construction of databases.

\section{Ethics approval and consent to participate}

The present study was approved by the Ethics Committee of Nanjing Medical University Cancer Centre (Nanjing, China). All patients provided written informed consent. All specimens were handled and stored anonymously according to ethical and legal standards.

\section{Patient consent for publication}

All patients provided written informed consent.

\section{Competing interests}

The authors declare that they have no competing interests.

\section{References}

1. Giri S, Pathak R, Aryal MR, Karmacharya P, Bhatt VR and Martin MG: Incidence trend of esophageal squamous cell carcinoma: An analysis of Surveillance Epidemiology, and End Results (SEER) database. Cancer Causes Control 26: 159-161, 2015.

2. Lin Y, Totsuka Y, Shan B, Wang C, Wei W, Qiao Y, Kikuchi S, Inoue $\mathrm{M}$, Tanaka $\mathrm{H}$ and $\mathrm{He} \mathrm{Y}$ : Esophageal cancer in high-risk areas of China: Research progress and challenges. Ann Epidemio 27: 215-221, 2017.

3. Siegel RL, Miller KD and Jemal A: Cancer statistics, 2015. CA Cancer J Clin 65: 5-29, 2015.

4. Diederichs S, Bäumer N, Ji P, Metzelder SK, Idos GE, Cauvet T, Wang W, Möller M, Pierschalski S, Gromoll J, et al: Identification of interaction partners and substrates of the cyclin A1-CDK2 complex. J Biol Chem 279: 33727-33741, 2004.

5. Ji P, Agrawal S, Diederichs S, Bäumer N, Becker A, Cauvet T, Kowski S, Beger C, Welte K, Berdel WE, et al: Cyclin A1, the alternative A-type cyclin, contributes to G1/S cell cycle progression in somatic cells. Oncogene 24: 2739-2744, 2005.

6. Müller-Tidow C, Ji P, Diederichs S, Potratz J, Bäumer N, Köhler G, Cauvet T, Choudary C, van der Meer T, Chan WY, et al: The cyclin A1-CDK2 complex regulates DNA double-strand break repair. Mol Cell Biol 24: 8917-8928, 2004.

7. Rivera A, Mavila A, Bayless KJ, Davis GE and Maxwell SA: Cyclin A1 is a p53-induced gene that mediates apoptosis, G2/M arrest, and mitotic catastrophe in renal, ovarian, and lung carcinoma cells. Cell Mol Life Sci 63: 1425-1439, 2006.

8. Yang R, Müller C, Huynh V, Fung YK, Yee AS and Koeffler HP: Functions of cyclin A1 in the cell cycle and its interactions with transcription factor E2F-1 and the Rb family of proteins. Mol Cell Biol 19: 2400-2407, 1999.

9. Liu D, Matzuk MM, Sung WK, Guo Q, Wang P and Wolgemuth DJ: Cyclin A1 is required for meiosis in the male mouse. Nat Genet 20: 377-380, 1998.

10. Krämer A, Hochhaus A, Saussele S, Reichert A, Willer A and Hehlmann R: Cyclin A1 is predominantly expressed in hematological malignancies with myeloid differentiation. Leukemia 12: 893-898, 1998.

11. Yang B, Miao S, Zhang LN, Sun HB, Xu ZN and Han CS: Correlation of CCNA1 promoter methylation with malignant tumors: A meta-analysis introduction. Biomed Res Int 2015: $134027,2015$.

12. Yanatatsaneejit $\mathrm{P}$, Chalermchai $\mathrm{T}$, Kerekhanjanarong $\mathrm{V}$, Shotelersuk K, Supiyaphun P, Mutirangura A and Sriuranpong V: Promoter hypermethylation of CCNA1, RARRES1, and HRASLS3 in nasopharyngeal carcinoma. Oral Oncol 44: 400-406, 2008.

13. Yang N, Eijsink JJ, Lendvai A, Volders HH, Klip H, Buikema HJ, van Hemel BM, Schuuring E, van der Zee AG and Wisman GB: Methylation markers for CCNA1 and C13ORF18 are strongly associated with high-grade cervical intraepithelial neoplasia and cervical cancer in cervical scrapings. Cancer Epidemiol Biomarkers Prev 18: 3000-3007, 2009. 
14. Zuo Q, Zheng W, Zhang J, Pan Z, Liu Y, Long H, Fan P, Guo C, $\mathrm{Li} \mathrm{F}$ and Shao R: Methylation in the promoters of HS3ST2 and CCNA1 genes is associated with cervical cancer in Uygur women in Xinjiang. Int J Biol Markers 29: e354-e362, 2014

15. Müller C, Readhead C, Diederichs S, Dos G, Yang R, Tidow N, Serve H, Berdel WE and Koeffler HP: Methylation of the cyclin A1 promoter correlates with gene silencing in somatic cell lines, while tissue-specific expression of cyclin A1 is methylation independent. Mol Cell Biol 20: 3316-3329, 2000.

16. Cho NH, Choi YP, Moon DS, Kim H, Kang S, Ding O, Rha SY, Yang YJ and Cho SH: Induction of cell apoptosis in non-small cell lung cancer cells by cyclin A1 small interfering RNA. Cancer Sci 97: 1082-1092, 2006.

17. Chujan S, Kitkumthorn N, Siriangkul S and Mutirangura A CCNA1 promoter methylation: A potential marker for grading Papanicolaou smear cervical squamous intraepithelial lesions. Asian Pac J Cancer Prev 15: 7971-7975, 2014.

18. Farhadieh RD, Smee R, Rees CG, Salardini A, Eggleton S, Yang JL and Russell PJ: Mutant p53 and cyclin A1 protein expression in primary laryngeal squamous cell carcinomas do not correlate to second primary tumours of the head and neck. ANZ J Surg 79: 48-54, 2009.

19. Weiss D, Koopmann M, Basel T and Rudack C: Cyclin A1 shows age-related expression in benign tonsils, HPV16-dependent overexpression in HNSCC and predicts lower recurrence rate in HNSCC independently of HPV16. BMC Cancer 12: 259, 2012.

20. Huang KC, Yang J, Ng MC, Ng SK, Welch WR, Muto MG, Berkowitz RS and Ng SW: Cyclin A1 expression and paclitaxel resistance in human ovarian cancer cells. Eur J Cancer 67: 152-163, 2016

21. Arsenic R, Braicu EI, Letsch A, Dietel M, Sehouli J, Keilholz U and Ochsenreither S: Cancer-testis antigen cyclin A1 is broadly expressed in ovarian cancer and is associated with prolonged time to tumor progression after platinum-based therapy. BMC Cancer 15: 784, 2015.

22. Klajic J, Busato F, Edvardsen H, Touleimat N, Fleischer T Bukholm I, Børresen-Dale AL, Lønning PE, Tost $\mathrm{J}$ and Kristensen VN: DNA methylation status of key cell-cycle regulators such as CDKNA2/p16 and CCNA1 correlates with treatment response to doxorubicin and 5-fluorouracil in locally advanced breast tumors. Clin Cancer Res 20: 6357-6366, 2014.

23. Sobin LH, Gospodarowicz MK and Wittekind C: International Union against Cancer (UICC) TNM classification of malignant tumours. Wiley-Liss, New York, pp73-76, 2010.

24. Bosman FT, Carneiro F, Hruban RH and Theise ND: WHO Classification of Tumours of the digestic system, 4th edition. Lyon, IARC press, pp417, 2010.

25. Livak KJ and Schmittgen TD: Analysis of relative gene expression data using real-time quantitative PCR and the 2(-Delta Delta C(T)) method. Methods 25: 402-408, 2001

26. Maziéres J, Brugger W, Cappuzzo F, Middel P, Frosch A, Bara I, Klingelschmitt $\mathrm{G}$ and Klughammer B: Evaluation of EGFR protein expression by immunohistochemistry using $\mathrm{H}$-score and the magnification rule: Re-analysis of the SATURN study. Lung Cancer 82: 231-237, 2013

27. Müller-Tidow C, Diederichs S, Schrader MG, Vogt U, Miller K, Berdel WE and Serve H: Cyclin A1 is highly expressed in aggressive testicular germ cell tumors. Cancer Lett 190: 89-95, 2003.

28. Wennhold K, Theurich S and von Bergwelt-Baildon $\mathrm{M}$ : Cyclin A1, a promising tumor antigen: The devil is in the amino acids. Expert Rev Anticancer Ther 13: 243-245, 2013.
29. Ochsenreither S, Majeti R, Schmitt T, Stirewalt D, Keilholz U, Loeb KR, Wood B, Choi YE, Bleakley M, Warren EH, et al: Cyclin-A1 represents a new immunogenic targetable antigen expressed in acute myeloid leukemia stem cells with characteristics of a cancer-testis antigen. Blood 119: 5492-5501, 2012.

30. Munari E, Chaux A, Maldonado L, Compérat E, Varinot J, Bivalacqua TJ, Hoque MO and Netto GJ: Cyclin A1 expression predicts progression in $\mathrm{pT} 1$ urothelial carcinoma of bladder: A tissue microarray study of 149 patients treated by transurethral resection. Histopathology 66: 262-269, 2015.

31. Wegiel B, Bjartell A, Tuomela J, Dizeyi N, Tinzl M, Helczynski L, Nilsson E, Otterbein LE, Härkönen P and Persson JL: Multiple cellular mechanisms related to cyclin A1 in prostate cancer invasion and metastasis. J Natl Cancer Inst 100: 1022-1036, 2008.

32. Ekberg J, Holm C, Jalili S, Richter J, Anagnostaki L, Landberg G and Persson JL: Expression of cyclin A1 and cell cycle proteins in hematopoietic cells and acute myeloid leukemia and links to patient outcome. Eur J Haematol 75: 106-115, 2005.

33. Holm C, Ora I, Brunhoff C, Anagnostaki L, Landberg G and Persson JL: Cyclin A1 expression and associations with disease characteristics in childhood acute lymphoblastic leukemia. Leuk Res 30: 254-261, 2006.

34. Marlow LA, von Roemeling CA, Cooper SJ, Zhang Y, Rohl SD, Arora S, Gonzales IM, Azorsa DO, Reddi HV, Tun HW, et al: Foxo3a drives proliferation in anaplastic thyroid carcinoma through transcriptional regulation of cyclin A1: A paradigm shift that impacts current therapeutic strategies. J Cell Sci 125: 4253-4263, 2012.

35. Hsia DA, Tepper CG, Pochampalli MR, Hsia EY, Izumiya C, Huerta SB, Wright ME, Chen HW, Kung HJ and Izumiya Y: KDM8, a H3K $36 \mathrm{me} 2$ histone demethylase that acts in the cyclin A1 coding region to regulate cancer cell proliferation. Proc Natl Acad Sci USA 107: 9671-9676, 2010.

36. Liu Y, Huang Y and Zhu GZ: Cyclin A1 is a transcriptional target of PITX2 and overexpressed in papillary thyroid carcinoma. Mol Cell Biochem 384: 221-227, 2013.

37. Wegiel B, Bjartell A, Culig Z and Persson JL: Interleukin-6 activates $\mathrm{PI} 3 \mathrm{~K} / \mathrm{Akt}$ pathway and regulates cyclin A1 to promote prostate cancer cell survival. Int J Cancer 122: 1521-1529, 2008.

38. Wegiel B, Bjartell A, Ekberg J, Gadaleanu V, Brunhoff C and Persson JL: A role for cyclin A1 in mediating the autocrine expression of vascular endothelial growth factor in prostate cancer. Oncogene 24: 6385-6393, 2005.

39. Miftakhova R, Hedblom A, Semenas J, Robinson B, Simoulis A, Malm J, Rizvanov A, Heery DM, Mongan NP, Maitland NJ, et al: Cyclin A1 and P450 aromatase promote metastatic homing and growth of stem-like prostate cancer cells in the bone marrow. Cancer Res 76: 2453-2464, 2016.

40. Syed Khaja AS, Dizeyi N, Kopparapu PK, Anagnostaki L, Härkönen P and Persson JL: Cyclin A1 modulates the expression of vascular endothelial growth factor and promotes hormone-dependent growth and angiogenesis of breast cancer. PLoS One 8: e72210, 2013.

This work is licensed under a Creative Commons Attribution-NonCommercial-NoDerivatives 4.0 International (CC BY-NC-ND 4.0) License. 